\title{
The Preferences and Factors Affecting Participation in Continuing Medical Education (CME) of Surgeons and Postgraduate Surgical Trainees in a Tertiary Care Hospital Setting.
} Gunarathna I.N, MBBS ${ }^{1}$, Wickramasinghe D.P, $\mathrm{MBBS}^{1}$, Samarasekera D.N, MBBS, MS, FRCS(Ed.\&Eng.) $)^{2}$

1 Research Assistant, University Surgical Unit, The National Hospital of Sri Lanka.

2 Professor of Surgery, University Surgical Unit, The National Hospital of Sri Lanka.

\begin{abstract}
Introduction: In an environment with constant rapid advancement, surgeons need to update their knowledge and skills. Apart frominitial undergraduate and post graduate training, the importance of CME over the subsequent years is self explanatory

Method: A validated, self administered questionnaire was given to consultant surgeons and postgraduate trainees (PGTs) in General Surgery at the National Hospital of Sri Lanka. This questionnaire assessed four main aspects regarding CME; demographic data, current involvement, order of preference and factors affecting participation.

Results: Of the 35 respondents, 24 were PGTs. There was no statistically significant difference between PGTs and consultants in relation to their current commitment towards CME $(p=0.51)$ or the time they would like to spend $(p=0.236)$. PGTs spent more time on group CME activity whereas consultants spent more time on individual CME activities. For the majority, the availability of free time was the main factor affecting participation. Cost and distance were limiting factors for $58.3 \%$ and $29 \%$ of the PGTs respectively.
\end{abstract}

Conclusion: There was no statistically significant difference between the two groups in the current commitment or the time they wish to spend on CME. As a significant number of trainees indicated financial and location constraints, the College should look into addressing these problems.

Key words: Surgical education; Training; Continuous medical education.

\section{Introduction}

In an environment with constant rapid advancement of surgical techniques, surgeons need to update their knowledge and skills for optimal patient care and improved clinical

Correspondnce: D.N.Samarasekera, University Surgical Unit, The

National Hospital of Sri Lanka.

Email: samarasekera58@yahoo.co.uk

The Sri Lanka Journal of Surgery 2010; 28(2):15-18. outcome. Compared to the initial 5 years of medical education and 4-5 years of post graduate training, the importance of CME over the subsequent years is self explanatory and thus described as "the final part of the education continuum" [1]. Therefore it is widely accepted that one of the primary objectives of undergraduate medical education is to inculcate the habit of life long learning [2].

A study by Goulet et al [3] showed that, compared to young physicians, older physicians maintained their clinical competence by 
participating in different continuing medical education (CME) activities. Previous studies have also shown a change in CME activity with increasing age [4]. Thus, CME activities for surgeons and postgraduate trainees should be planned according to their preferences and needs. Two studies have shown that appropriate and accurate need assessment contributes greatly to the success of CME programs $[5,6]$. Thus assessment of preferences, practices and factors affecting participation in CME for surgeons and postgraduate surgical trainees in a tertiary care hospital setting will greatly contribute to achieve the most successful and effective CME activity. Preferences and data about the needs of each group will help CME planners to address each group to improve the outcome.

The objectives of this study were, to determine the time spent on CME activities by surgeons and postgraduate trainees in surgery and to identify the preferences and practices affecting their participation in CME activities.

\section{Methods}

\section{Setting and participants}

The study population comprised consultant surgeons and postgraduate trainees in General Surgery at the National Hospital of Sri Lanka (NHSL). The questionnaires were distributed at lectures, workshops and monthly morbidity and mortality meetings after explaining the purpose of the research. All participants were assured confidentiality.

An Ethical Review Committee of the National Hospital of Sri Lanka approved the study.

\section{Questionnaire}

The participants were given a self administered validated questionnaire developed to assess surgeons' participation in continuing medical education [7]. This questionnaire assessed four main aspects regarding CME; demographic data, current involvement, order of preference and factors affecting participation. All participants were asked to indicate the total number of hours they spent on CME activities and hours they spent on each CME activity. The participants were also asked to mention how much time they would prefer to spend on each CME activity from a list of 14 common CME activities. They were also asked to note their order of preference from 1 to 10 for the 10 most preferred CME activities in the list.

The final question was open-ended and asked respondents about factors affecting their participation in CME activities.

\section{Table 1. Types of CME activity}

\begin{tabular}{|c|c|c|}
\hline $\begin{array}{c}\text { CME activity } \\
\text { (Minutes per month) }\end{array}$ & ڤ & 泀 \\
\hline $\begin{array}{l}\text { Reading, e.g. journal articles, } \\
\text { textbooks }\end{array}$ & 1960.0 & 1527.2 \\
\hline Attending surgical conference(s) & 215.4 & 163.0 \\
\hline $\begin{array}{l}\text { Listening to audiotapes or watch } \\
\text { videotapes }\end{array}$ & 43.6 & 183.0 \\
\hline $\begin{array}{lcr}\text { Informal } & \text { discussions } & \text { with } \\
\text { colleagues } & \text { about } & \text { surgical } \\
\text { management } & & \end{array}$ & 705.6 & 177.0 \\
\hline $\begin{array}{l}\text { Teaching undergraduates, } \\
\text { postgraduates, peers }\end{array}$ & 430.8 & 616.3 \\
\hline $\begin{array}{l}\text { Conducting a clinical audit of } \\
\text { own practice }\end{array}$ & 22.1 & 114.0 \\
\hline $\begin{array}{l}\text { Visiting another department to } \\
\text { improve skills }\end{array}$ & 23.4 & 12.0 \\
\hline Writing journal articles & 31.3 & 51.0 \\
\hline Attending journal club & 86.1 & 60.0 \\
\hline $\begin{array}{l}\text { Attending training in surgical } \\
\text { skills laboratory }\end{array}$ & 67.8 & 15.0 \\
\hline $\begin{array}{l}\text { Producing audiovisual materials } \\
\text { for others }\end{array}$ & 5.2 & 36.0 \\
\hline $\begin{array}{l}\text { Attending hospital-based clinical } \\
\text { or peer review meetings }\end{array}$ & 148.6 & 63.0 \\
\hline Attending formal course & 133.0 & 24.0 \\
\hline $\begin{array}{l}\text { Participating in internet-based or } \\
\text { formal learning CME }\end{array}$ & 300.0 & 392.7 \\
\hline
\end{tabular}




\section{Statistical analysis}

The data were analyzed using SPSS version 18 (SPSS for Windows, Rel. 18. Chicago, USA). The Mann Whitney test was used to assess differences between the two groups. A value of ? 0.05 was considered significant.

\section{Results}

There were a total of 35 respondents; i.e. 24 post graduate trainees in General Surgery and 11 consultant surgeons. The median age of the two groups was 33.7 years (range 30-40) and 49.7 years (range 41-58) respectively. Types of CME activity are shown in table 1 .

There was no statistically significant difference between post graduate trainees and consultants in relation to their current commitment towards CME activities (40.28 hrs vs. $56.45 \mathrm{hrs}$, $\mathrm{p}=0.51)$. Postgraduate $(\mathrm{PG})$ trainees indicated that they had spent a median of 40.28 hours (range 2-110 hours) on CME per month whereas consultants had spent a median of 40.71 hours (range 1.5-125 hours) on CME activities per month. No significant difference was seen between consultants and PGs in relation to hours they wished to spend on $\mathrm{CME}$ activities. $(p=0.236)$. PGs indicated that the median time they would like to spend on CME was 56.45 hours (range 8-150) per month while consultants indicated that they would like to spend a median of 47.95 hours (range 3-125) per month.

$91 \%$ of consultants and $75 \%$ of $\mathrm{PG}$ trainees identified availability of free time as a factor affecting their participation in CME. $58 \%$ of PG trainees and $9 \%$ of consultants indicated that they could not afford the programs. $36 \%$ of consultants and $29 \%$ of PG trainees indicated that distance to the location from their work place affected participation in CME activities (Figure 1).

\section{Discussion}

Our study explores the preferences and potential limiting factors in CME participation in the surgical community. There is very little data available on the CME activities of doctors from developing countries and the data for surgeons is scarce. A study in Australia showed that younger doctors spent more time than older doctors on CME activities [7]. Our findings contradict this, but it is important to note that the difference we observed was not statistically significant and that younger surgeons (i.e. post graduate trainees) would like to spend more time on CME. The results of a Canadian study have shown that older physicians spend more time on individual CME activities whereas the younger physicians spend more time on group CME activities [3], and this fact was evident in our sample as well (for postgraduate trainees and consultants respectively; i.e. using audio/video tapes 43 vs. $180 \mathrm{~min}$, informal discussions $705 \mathrm{mins}$ vs. $177 \mathrm{mins}$ ). Another study [7] among surgeons in New South Wales, Australia, found that most of the time was spent on reading and our study also shows that reading is one aspect that our doctors prefer.

Chambers et al [4] studied barriers for CME participation among anaesthetists in Scotland and found funding was less of a limitation for those working in district general hospitals. Another study carried out among physicians in the state of Oregon, USA, showed that the apparent disparity between the type of $\mathrm{CME}$ method the learner prefers and the type of CME activity organized by the institution is a barrier for participation [8]. Stafford et al [9] pointed out that non-fee levying and local continuing

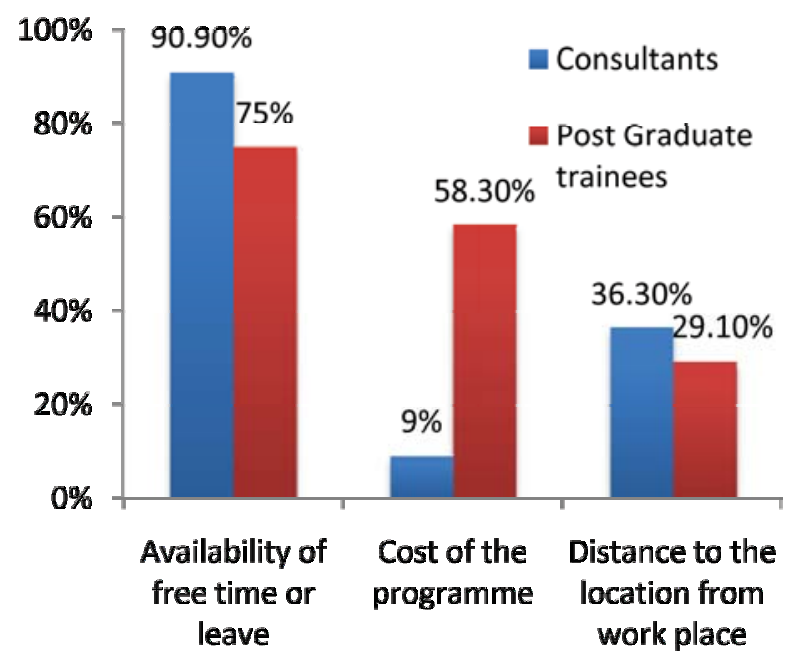

Figure1: Main factors affecting CME participation 
medical education did not always guarantee high participation in CME activities.

This may be due to the fact that surgeons have barriers such as time away from a practice to attend $\mathrm{CME}$ activities. Among the many CME activities, the evidence shows that interactive educational sessions were more effective than non- interactive activities. [10,11,12].

It is important to acknowledge that our study is a self reported account of CME participation and therefore, the possibility of overestimation is unavoidable. In addition, reading, which was rated as the number one activity, does not generate proof of attendance or participation. Perhaps a study that uses CME participation data may be able to overcome this factor.

\section{Conclusions}

Since the majority (58\%) of PG trainees indicated financial constraints preventing them from attending CME programs, we feel that the College of Surgeons of Sri Lanka should consider sponsoring or subsidizing PG trainees in need.

Since a notable number of PG trainees $(29 \%)$ indicated difficulty in travelling to the $\mathrm{CME}$ destination, we suggest regular CME programs to be conducted on rotation in all the major training hospitals, so that those trainees working in centres far away from the College or tertiary care centres would also have the opportunity to participate in such programs.

\section{References}

1. Bennett N.L. et al. Continuing medical education: a new vision of the professional development of physicians. Acad Med, 2000; 75:1167-72.

2. Kassebaum, D.G. On the connection between CME and education in medical schools. Acad Med, 1993; 68:668-9.
3. Goulet F. et al. Participation in CME activities. Can Fam Physician, 1998; 44:541-8.

4. Chambers W.A., Ferguson K. ,Prescott G.J. Continuing medical education by anaesthetists in Scotland: activities, motivation and barriers. Anaesthesia, 2000; 55:1192-7.

5. Laxdal O.E. Needs assessment in continuing medical education: a practical guide. J Med Educ, 1982; 57:827-34.

6. Weinberg A.D. et al. Perceived ability versus actual ability: a problem for continuing medical education. Annu Conf Res Med Educ, 1977; 16:79-84.

7. Young J.M., Hollands MJ, Solomon MJ. Surgeons' participation in continuing medical education: is it evidence-based? Med Educ, 2006; 40:423-9.

8. Bower E.A. et al. Barriers to innovation in continuing medical education. J Contin Educ Health Prof. 2008; 28:148-56.

9. Stafford R.E. et al. Free and local continuing medical education does not guarantee surgeon participation in maintenance of certification learning activities. Am Surg, 2010; 76:692-6.

10. Thomson O'Brien M.A, et al. Continuing education meetings and workshops: effects on professional practice and health care outcomes. Cochrane Database Syst Rev, 2001(2):CD003030.

11. Forsetlund L. et al. Continuing education meetings and workshops: effects on professional practice and health care outcomes. Cochrane Database Syst Rev, 2009(2):p.CD003030.

12. Bellolio M.F., Stead L.G. Evidence-based emergency medicine/systematic review abstract. Continuing education meetings and workshops: effects on professional practice and health care outcomes.Ann Emerg Med. 2009; 53(5):685-7. 